\title{
An approach to MDA - ComDeValCo framework
}

\author{
S. MotognA, I. LAZĂR and B. PÂRV
}

\section{ABSTRACT.}

Software design based on Model Driven Architecture can be essentially improved including agile principles as immediate execution and test first development. This paper shows how a concrete tool, the ComDeValCo framework, has been constructed and enhanced to support such an approach. The paper discusses in detail how the constructs for component models and for the dynamic execution environment have been introduced.

DEPARTMENT OF COMPUTER SCIENCE

"BABES-BOLYAI" UNIVERSITY

KOGALNICEANU 1, 40004 CLUJ-NAPOCA, ROMANIA

E-mail address: $\{$ motogna, ilazar, bparv\}@es.ubbcluj.ro 